\title{
Can alternative medicine do better than placebo?: Does it even matter?
}

\author{
Mark A. Moyad, MD, MPH
}

See related article on page 49

Can Urol Assoc J 2010;4(1):54-5

would like to express my appreciation to the editor of CUAJ for publishing an alternative medicine article and to the authors for completing an alternative medicine study in urology. ${ }^{1}$ Some people would argue that this trial is too small for publication, but I would argue that if the reader has ever attempted to garner funding for any alternative medicine trial that this trial is more than adequate. This article is another example of the change in research objectives; there is more research in alternative medicine now than there was when I first started working and teaching in the field of urology about 15 years ago. Note my use of the word "alternative medicine" and not the more politically correct "integrative/complementary medicine" that some use to give the appearance of a more gentle and standardized treatment or approach. It was the late Dr. William Fair from Memorial Sloan-Kettering Cancer Center who reminded me that when something alternative gets adequate research, it will no longer be considered alternative but mainstream. For example, consider the use of calcium and vitamin $\mathrm{D}$ supplements for men receiving androgen deprivation treatment (ADT) for prostate cancer. ${ }^{2}$

There seems to be a generalized belief that men with prostate cancer have a plethora of conventional safe options when dealing with hot flashes due to ADT. This could not be further from the truth, which was insightfully mentioned the CUAJ article by Al-Bareeq and colleagues. ${ }^{1}$ All currently used conventional options have serious potential questions and concerns. For example, progesterone-like agents, arguably one of the most effective and popular medications, can potentially cause weight gain, high density lipoprotein reductions, appetite stimulation, exacerbate the effects of sarcopenia, and may have negative impacts on bone health. ${ }^{3}$ Antiandrogens, selective serotonin reuptake inhibitors (SSRIs) and serotonin/norepinephrine reuptake inhibitors (SNRIs), and estrogens are not without their own overt toxicities and potential cardiovascular concerns; along with the now well-recognized side effects and current unresolved cardiovascular concerns of ADT itself. ${ }^{4-6}$ Anti-seizure medications require dose-escalation and may exacerbate already well-known side effects of ADT, such as fatigue. ${ }^{7,8}$
What is the clinician and patient to do after weighing the benefits and risks? Arguably, alternative medicine remedies for hot flashes are popular, but lack preliminary effective data in the ADT patient. However, 5 rules can guide future research and clinical suggestions to relieve hot flashes using conventional and alternative medicines.

First, whatever is effective in the breast cancer or postmenopausal literature is generally effective for male ADT patients. The progesterone agents and all others mentioned above were first tested and successful in large trials with women before being used in men. ${ }^{5}$

Second, whatever is not effective or safe in the breast cancer and postmenopausal literature is generally not effective and safe for male ADT patients. This is why I disagree with the use of Dong Quai in an ADT study because a welldone randomized trial in women in the 1990s and a recent well-designed trial found no affect on hot flashes beyond a placebo effect, whether Dong Quai was used alone or as part of a complex multi-ingredient intervention. ${ }^{9-11}$ Additionally, there have been potential issues of toxicity with this herbal product in general and with cancer patients, ${ }^{12,13}$ which is why it was admirable that the authors followed the patients closely for any coagulation changes. ${ }^{1}$ The bigger issue is why even test the efficacy of this compound in men on ADT?

Third, the placebo effect needs to be respected in medicine. Few conditions, other than hot flashes, garner more of a placebo effect in clinical trials so just trying to beat the placebo is a daunting task unless most patients have frequent and severe or very severe hot flashes, ${ }^{14}$ which was another limitation of this study. And, recent clinical research suggests an enhanced potential for a placebo effect with more frequent and severe hot flashes, ${ }^{15}$ which at least would suggest exactly what the authors concluded that Dong Quai has no relevant activity against hot flashes beyond an adequately constructed placebo.

Fourth, the best method of deciding who does and potentially does not qualify for hot flash medical interventions would be to first encourage patients to use a diary similar to what has been used for women. ${ }^{16,17}$ Thus, only men with moderate to very severe hot flashes which cannot be improved by lifestyle changes (e.g., lighter clothing, tem- 
perature changes, tolerance with time, exercise) or selfperceived trial and error modifications should be candidates for medicinal intervention after reviewing the risks and benefits with the patient. ${ }^{2,17}$ Thankfully, the true need for serious pharmacologic intervention is small as exemplified in this study and in my experience in men with ADT.

Fifth, we should always try to remember that heart health is tantamount to prostate health. We should never disregard the overall quality and quantity of life impact of any potential medicine to treat the side effect of another medicine, and that also includes cost issues. "First do no harm" and "If you are wrong it still should be right for the patient" are good mantras to follow. For example, again I generally do not recommend anything beyond diaries, lifestyle changes and the addition of several tablespoons of cheap dietary flaxseed daily for men (a well-tested, healthy and safe placebo-like product) or another heart healthy dietary agent for mild to moderate hot flashes because these interventions can at least promote heart healthy changes, mood, and have potential anti-proliferative effects in prostate cancer patients from clinical trials. ${ }^{18,19}$ Moderate to very severe hot flashes that truly affect daily routine and/or sleep can be treated with progesterone, cyproterone, venlafaxine or another agent that the clinician knows has a history of almost immediate efficacy. ${ }^{2,20,21}$ However, the risk of any cardiovascular abnormalities needs to be monitored by the specialist and/or primary care physician.

At the end of the day, I would ask you to consider what is wrong with a safe and effective placebo effect in men with ADT, especially in the area of hot flashes where it is not unusual to witness a $50 \%$ response to such an apparently inert intervention. ${ }^{14}$ It is not as if a placebo effect implies no effect because the clinical impact or subjective benefit is real, but clinicians are just not able to explain specifically why the benefit is occurring in a particular patient. Who cares if we do not know how it is happening, as long as it is occurring in a safe, cheap, effective and heart healthy manner in your patients on ADT.

Jenkins/Pokempner Director of Preventive \& Alternative Medicine, University of Michigan Medical Center, Department of Urology, Ann Arbor, MI

Competing interests: None declared.

This paper has been peer-reviewed.

\section{References}

1. Al-Bareeq RJ, Ray AA, Nott L, et al. Dong Quai (angelica sinensis) in the treatment of hot flashes for men on androgen deprivation therapy: results of a randomized double-blind placebo controlled trial. Can Urol Assoc J 2010; 1:49-53.

2. Moyad MA. Promoting general health during androgen deprivation therapy (ADT): a rapid 10-step review for your patients. Urol Oncol 2005;23:56-64.

3. Bordeleau L, Pritchard K, Goodwin P, et al. Therapeutic options for the management of hot flashes in breast cancer survivors: an evidence-based review. Clin Ther 2007;29:230-41.

4. Chen $\mathrm{KC}$, Peng $\mathrm{CC}$, Hsieh HM, et al. Antiandrogenic therapy can cause coronary arterial disease. Int $\mathrm{J}$ Urol 2005;12:886-91.

5. Moyad MA. Complementary/alternative therapies for reducing hot flashes in prostate cancer patients: reevaluating the existing indirect data from studies of breast cancer and postmenopausal women. Urology 2002;59(4Suppl1):20-33.

6. Kintzel PE, Chase SL, Schultz LM, et al. Increased risk of metabolic syndrome, diabetes mellitus, and cardiovascular disease in men receiving androgen deprivation therapy for prostate cancer. Pharmacotherapy 2008;28:1511-22

7. Loprinzi CL, Dueck AC, Khoyratty BS, et al. A phase III randomized, double-blind, placebo-controlled trial of gabapentin in the management of hot flashes in men. Ann Oncol 2009;20:542-9.

8. Pandya KJ, Morrow GR, Roscoe JA, et al. Gabapentin for hot flashes in 420 women with breast cancer: a randomized double-blind placebo-controlled trial. Lancet 2005;366:818-24.

9. Hirata JD, Swiersz $L M, Z$ Zell B, et al. Does dong quai have estrogenic effects in postmenopausal women? A double-blind, placebo-controlled trial. Fertil Steril 1997;68:981-6.

10. Newton KM, Reed SD, LaCroix AZ, et al. Treatment of vasomotor symptoms of menopause with black cohosh, multibotanicals, soy, hormone therapy, or placebo: a randomized trial. Ann Intern Med 2006; 145:869-79

11. Cheema D, Coomarasamy A, E-Toukhy T. Non-hormonal therapy of post-menopausal vasomotor symptoms: a structured evidence-based review. Arch Gynecol Obstet 2007;276:463-9.

12. Lau CB, Ho TC, Chan TW, et al. Use of dong quai (Angelica sinensis) to treat peri- or postmenopausal symptoms in women with breast cancer: Is it appropriate? Menopause 2005;12:734-40.

13. Monograph. Angelica Sinensis. Altern Med Rev 2004;9:429-33.

14. Moyad MA. The placebo effect and randomized trials: analysis of conventional medicine. Urol Clin North Am 2002;29:125-33

15. Jones JM, Loprinzi CL, Qin R, et al. Hot flash placebo responses. Related to baseline hot flash frequency? J Clin Oncol 2009;27:515s, abstr 9628.

16. Hanisch $\mathrm{U}$, Palmer SC, Marcus SC, et al. Comparison of objective and patient-reported hot flash measures in men with prostate cancer. J Support Oncol 2009;7:131-5.

17. Moyad MA. Promoting wellness for patients with prostate cancer. Second Edition. Ann Arbor Media Group, 2009.

18. Demark-Wahnefried W, Polascik TJ, George SL, et al. Flaxseed supplementation (not dietary fat restriction) reduces prostate cancer proliferation rates in men presurgery. Cancer Epidemiol Biomarkers Prev 2008:3577-87.

19. Pan A, Yu D, Demark-Wahnefried W, et al. Meta-analysis of the effects of flaxseed interventions on blood lipids. Am I Clin Nutr 2009;90:288-97.

20. Langenstroer $P$, Kramer B, Cutting B, et al. Parenteral medroxyprogesterone for the management of luteinizing hormone releasing hormone induced hot flashes in men with advanced prostate cancer. J Urol 2005; 174:642-5.

21. Irani J, Salomon L, Oba R, et al. Efficacy of venlafaxine, medroxyprogesterone acetate, and cyproterone acetate for the treatment of vasomotor hot flushes in men taking gonadotropin releasing hormone analogues for prostate cancer: a double-blind, randomized trial. Lancet Oncol 2009, Dec 4 [Epub ahead of print].

Correspondence: Dr. Mark Moyad, University of Michigan Medical Center, Department of Urology, Urology Surgery Section, 2916 TC SPC 5330, Ann Arbor, Ml; moyad@umich.edu 